\title{
Alterações isoenzimáticas em sementes de cultivares de soja em diferentes condições de armazenamento
}

\author{
Everson Reis Carvalho(1), Denilson Paulo da Rosa Mavaieie(1), João Almir Oliveira(1), \\ Marcos Vinícios de Carvalho( ${ }^{(1)}$ e Antônio Rodrigues Vieira(2)
}

\begin{abstract}
(1)Universidade Federal de Lavras (Ufla), Departamento de Agricultura, Setor de Sementes, Caixa Postal 3.037, CEP 37200-000 Lavras, MG, Brasil. E-mail: eversonreiscarvalho@hotmail.com, dmavaieie@gmail.com, jalmir@dag.ufla.br, vinicioscarvalho.ufla@hotmail.com ${ }^{(2)} E m p r e s a$ de Pesquisa Agropecuária de Minas Gerais, Centro Tecnológico do Sul de Minas, Campus da Ufla, Caixa Postal 176, CEP 37200-000 Lavras, MG, Brasil. E-mail: arvieira@epamig.ufla.br
\end{abstract}

Resumo - O objetivo deste trabalho foi determinar alterações fisiológicas e isoenzimáticas em sementes de genótipos de soja, em diferentes condições de armazenamento. Utilizou-se o delineamento experimental inteiramente casualizado com quatro repetições, em arranjo fatorial com seis cultivares de soja (TMG 1176, TMG 1179, TMG 132, TMG 133, TMG 115 e GB 874) e cinco periodos de armazenamento (0, 2, 4, 6 e 8 meses), em dois ambientes de armazenamento (câmara fria e seca, a $10^{\circ} \mathrm{C}$ e $50 \%$ de umidade relativa; e armazém convencional, em condições não controladas). A qualidade fisiológica foi avaliada por meio de testes de germinação, de envelhecimento acelerado e de frio. As expressões isoenzimáticas determinadas foram as de malato desidrogenase (MDH), álcool desidrogenase (ADH), esterase (EST), isocitrato liase (ICL), superóxido dismutase (SOD) e peroxidase (PO). Sementes de soja armazenadas em câmara fria e seca conservaram sua qualidade fisiológica. Após seis meses de armazenamento, em condições não controladas, a qualidade das sementes e as atividades isoenzimáticas de $\mathrm{MDH}, \mathrm{ADH}, \mathrm{EST}$, ICL, SOD e PO diminuíram. No armazenamento em câmara fria e seca, não ocorreu alteração nas sementes. Os genótipos de soja apresentam diferentes níveis de tolerância ao armazenamento e expressões isoenzimáticas.

Termos para indexação: Glycine max, câmara fria, enzimas, potencial de armazenamento.

\section{Isozyme alterations in soybean cultivar seeds at different storage conditions}

Abstract - The objective of this work was to determine the physiological and isozyme alterations in seeds of soybean genotypes, under different storage conditions. A completely randomized experimental design was used with four replicates, in a factorial arrangement with six soybean cultivars (TMG 1176, TMG 1179, TMG 132, TMG 133, TMG 115, and GB 874) and five storage times ( $0,2,4,6$, and 8 months), in two storage environments (a cold and dry chamber, at $10^{\circ} \mathrm{C}$ and $50 \%$ relative humidity; and a conventional warehouse, under uncontrolled conditions). Physiological quality was evaluated by the germination, accelerated aging, and cold tests. Isozyme expressions of malate dehydrogenase (MDH), alcohol dehydrogenase (ADH), esterase (EST), isocitrate lyase (ICL), superoxide dismutase (SOD), and peroxidase (PO) were determined. Soybean seeds stored in cold and dry chambers maintained their physiological quality. After six months storage under uncontrolled conditions, seed quality and isozyme expressions of MDH, ADH, EST, ICL, SOD, and PO lowered. There was no alteration on seed stored in cold and dry chambers. Soybean genotypes show different tolerance levels to storage and isozyme expression.

Index terms: Glycine max, cold chamber, enzymes, storability.

\section{Introdução}

Para a obtenção de produtividade satisfatória da soja, é necessária a utilização de sementes com elevada qualidade, entre outros fatores. Scheeren et al. (2010) verificaram que a produtividade resultante de lotes de sementes com alto vigor, pode ser $9 \%$ superior à de sementes com baixo vigor.

No período pós-colheita, as sementes necessitam de armazenamento em condições e embalagens adequadas, para a manutenção da qualidade até o momento da semeadura. Em algumas regiões do Brasil, em geral, as condições ambientais são adversas para o armazenamento de sementes, em razão de altas temperaturas que podem estar associadas com elevada umidade relativa do ar. Lima et al. (2014) constataram que o ambiente natural não é indicado para o armazenamento de sementes de girassol. Forti et al. (2010) verificaram evolução dos danos por umidade e, consequentemente, diminuição do potencial fisiológico 
durante o armazenamento, efeitos estes que são maiores nas sementes armazenadas em ambiente não controlado e menores nas armazenadas em câmara fria - a $65 \%$ de umidade relativa (UR) e $10^{\circ} \mathrm{C}$. Vieira et al. (2013a) concluíram que o armazenamento a $25^{\circ} \mathrm{C}$ por 12 meses reduziu o potencial fisiológico de sementes de soja, e que a qualidade fisiológica foi mantida a $10^{\circ} \mathrm{C}$ (45 a $50 \%$ UR do ar).

Além da temperatura, da umidade relativa do ar do armazém e do teor de água na semente, a manutenção da qualidade das sementes em armazenamento também é influenciada por diferenças entre genótipos quanto ao nível de germinação e de vigor ao longo do armazenamento (Martins-Filho et al., 2001). Portanto, o período de viabilidade da semente depende tanto de características genéticas quanto de efeitos ambientais, durante as fases de desenvolvimento, colheita, processamento e armazenamento (Gris et al., 2010).

Atualmente, há preocupação quanto à seleção de genótipos de soja cujas sementes tenham maior potencial de armazenamento, para que a qualidade fisiológica se mantenha até o momento da semeadura. No entanto, estudos que relacionam diferentes níveis de tolerância ao armazenamento entre cultivares de soja e suas causas são escassos. Assim, o estudo da expressão de isoenzimas, ao longo do armazenamento, pode ser útil.

Ávila et al. (2012) verificaram que o vigor e a viabilidade apresentaram tendência contrária à atividade dos agentes antioxidantes, ao longo do envelhecimento acelerado, até 48 horas. Vieira et al. (2013b) observaram que as atividades da malato desidrogenase $(\mathrm{MDH})$ e esterase (EST) diminuíram após o sexto mês de armazenamento de sementes de soja, com o desaparecimento das bandas, nas sementes armazenadas aos 9 e 12 meses de armazenamento a $25^{\circ} \mathrm{C}$. Para a glutamato desidrogenase, esta redução só foi constatada a partir de nove meses de armazenamento. As análises enzimáticas foram sensíveis quanto ao potencial fisiológico, o que indica o início da deterioração das sementes, em consequência do período de armazenamento. Timóteo \& Marcos Filho (2013) constataram que o potencial de armazenamento é variável, conforme o genótipo de milho, e que a associação entre germinação, vigor e atividade de isoenzimas permite avaliar tal parâmetro com segurança. Há escassez de informações quanto ao potencial de armazenamento de sementes de soja e suas alterações bioquímicas durante o processo.
O objetivo deste trabalho foi determinar alterações fisiológicas e isoenzimáticas em sementes de genótipos de soja, em diferentes condições de armazenamento.

\section{Material e Métodos}

$\mathrm{O}$ armazenamento das sementes sob condições não controladas (armazém convencional) foi realizado na empresa Sementes Arco Íris, em Alto Garças, Estado do Mato Grosso, Brasil. O armazenamento em câmara fria e seca $\left(10^{\circ} \mathrm{C}\right.$ e $50 \%$ UR) e as análises fisiológicas e bioquímicas das sementes foram realizados no Laboratório Central de Análise de Sementes, da Universidade Federal de Lavras (Ufla), Lavras, MG.

Foram utilizadas as seguintes cutivares de soja: TMG 1176 RR, TMG 1179 RR, TMG 132 RR, TMG 133 RR, TMG 115 RR e GB 874 RR. As sementes foram produzidas em condições edafoclimáticas semelhantes, na fazenda da empresa Sementes Arco Íris, em Alto Garças, MT (16 $6^{\circ} 56^{\prime} \mathrm{S}, 5^{\circ} 34^{\prime} \mathrm{W}$, altitude $767 \mathrm{~m}$ ). As sementes de todas as cultivares foram secas até atingir $12 \%$ de teor de água e beneficiadas em máquina de pré-limpeza, máquina de ar e peneiras, separador em espiral, padronizadora por tamanho, mesa de gravidade e embaladora. As sementes foram acondicionadas em embalagens de papel-kraft multifoliado. Foram utilizados lotes de sementes que apresentavam características iniciais semelhantes quanto à germinação e ao vigor.

As sementes foram divididas em duas porções e armazenadas sob duas condições: câmara fria e seca $\left(10^{\circ} \mathrm{C}\right.$ e $50 \%$ UR) e condições não controladas (armazém convencional). Os valores de temperatura e UR média foram $22^{\circ} \mathrm{C}$ e $73 \%$, respectivamente, durante o período de armazenamento entre junho e fevereiro do ano subsequente. A cada dois meses de armazenamento $(0,2,4,6$ e 8 meses), amostras de sementes inicialmente acondicionadas em embalagens distintas, referentes a cada época de avaliação, foram coletadas. As sementes foram avaliadas quanto à qualidade fisiológica em cada período de armazenamento, e parte delas foi armazenada a $-86^{\circ} \mathrm{C}$ para análises isoenzimáticas posteriores, que foram realizadas conjuntamente ao final do armazenamento.

A qualidade fisiológica foi estimada por meio dos testes de germinação, envelhecimento acelerado e de frio a seguir descritos. No teste de germinação, as sementes foram semeadas em papel germitest 
(3 folhas), umedecido com água destilada, em quantidade equivalente a 2,5 vezes o peso do papel seco. Os rolos montados foram mantidos em germinador a $25^{\circ} \mathrm{C}$. A avaliação foi efetuada aos cinco dias após a semeadura, e os resultados foram expressos em percentagem de plântulas normais (Regras para análise de sementes, 2009). O teste de envelhecimento acelerado foi conduzido em caixas de acrílico transparentes $(11,0 \times 11,0 \times 3,5 \mathrm{~cm})$, tipo gerbox, adaptadas com tela de alumínio suspensa, às quais foram adicionados $40 \mathrm{~mL}$ de água e uma camada única de sementes sobre toda a tela; em seguida, as caixas foram mantidas em câmara tipo BOD a $41^{\circ} \mathrm{C}$ por 48 horas (Marcos Filho, 1999); após este período, as sementes foram submetidas ao teste de germinação, conforme descrição anterior. No teste de frio, a semeadura foi efetuada em substrato solo + areia, à proporção $2: 1$, acondicionado em bandejas de plástico e umedecido a $60 \%$ da capacidade de retenção. Após a semeadura, as bandejas foram colocadas em câmara fria e seca $\left(10^{\circ} \mathrm{C}\right.$ e $\left.50 \% \mathrm{UR}\right)$, por cinco dias e, posteriormente, levadas para a câmara de crescimento vegetal a $25^{\circ} \mathrm{C}$, com fotoperíodo de 12 horas, por sete dias. Ao final, realizou-se a contagem do número de plântulas normais emergidas. Em laboratório, para os testes fisiológicos, quatro repetições técnicas de 50 sementes foram utilizadas para cada repetição biológica.

$\mathrm{Na}$ avaliação da expressão isoenzimática, foram utilizadas duas repetições técnicas de 50 sementes por repetição biológica. As sementes foram moídas em moinho refrigerado, com nitrogênio líquido e PVP (polivinilpirrolidona), e armazenadas a $-86^{\circ} \mathrm{C}$. Para a avaliação de cada isoenzima, foram pesadas $100 \mathrm{mg}$ do material. Antes da extração, realizou-se a lavagem das amostras para retirada do óleo, adicionaram-se $300 \mu \mathrm{L}$ de éter etílico e $300 \mu \mathrm{L}$ de água, com homogeneização em agitador vortex e repouso por $30 \mathrm{~min}$ em gelo; o material homogeneizado foi centrifugado em MPW-350R (MPW Med. Instruments, Varsóvia, Polônia) a $18.000 \mathrm{~g}$ por $30 \mathrm{~min}$, a $4^{\circ} \mathrm{C}$, tendo-se descartado o sobrenadante. Adicionaram-se $300 \mu \mathrm{L}$ do tampão de extração, tendo-se utilizado tampão fosfato para a extração da peroxidase; para as demais enzimas, utilizou-se tampão Tris $\mathrm{HCl}\left(0,2 \mathrm{~mol} \mathrm{~L}^{-1} \mathrm{pH} 8,0\right)$, e $0,1 \%$ de $\beta$-mercaptoetanol. O material foi colocado em geladeira por 12 horas e, depois, foi centrifugado a $18.000 \mathrm{~g}$ por $30 \mathrm{~min}$, a $4^{\circ} \mathrm{C}$ (Alfenas, 2006). Para a corrida eletroforética, realizada em cuba vertical MV20COMP (Omniphor, San Jose, CA, EUA) a $150 \mathrm{~V}$ por 6 horas, a $4^{\circ} \mathrm{C}$, aplicaram-se $60 \mu \mathrm{L}$ do sobrenadante à canaleta do gel. A eletroforese em géis de poliacrilamida, NATIVA-PAGE, foi desenvolvida em sistema descontínuo (4,5\% gel de concentração e 7,5\% gel de separação). Utilizou-se como sistema tampão gel/ eletrodo Tris-glicina $\mathrm{pH} 8,9$. Ao término da corrida, os géis foram revelados para as isoenzimas isocitrato liase (EC 4.1.3.1; ICL), de acordo com Santos (2013); e para a esterase (EC 3.1.1.1; EST), malato desidrogenase (EC 1.1.1.37; MDH), álcool desidrogenase (EC 1.1.1.1; $\mathrm{ADH})$, superóxido dismutase (EC 1.15.1.1; SOD) e peroxidase (EC 1.11.1.7; PO), de acordo com Alfenas (2006). A avaliação dos perfis isoenzimáticos foi realizada de acordo com a presença ou ausência de bandas e intensidade delas.

$\mathrm{O}$ delineamento experimental inteiramente casualizado foi utilizado em arranjo fatorial $6 \times 5 \times 2$, com seis cultivares de soja, cinco períodos de armazenamento e dois ambientes de armazenamento, com quatro repetições. Os dados foram submetidos à análise de variância com auxílio do programa Sisvar (Ferreira, 2011), a 5\% de probabilidade, pelo teste F. Quando pertinente, as médias foram comparadas pelo teste Scott-Knott, a 5\% de probabilidade, ou realizouse análise de regressão polinomial.

\section{Resultados e Discussão}

Houve interação tripla entre cultivar, ambiente e período de armazenamento para os testes de germinação, envelhecimento acelerado e frio, com coeficientes de variação (CV) de 3,22, 3,29 e 5,11\%, respectivamente.

Foi constatado comportamento quadrático para os valores de germinação, com pequena variação, em sementes da cultivar TMG 115, armazenadas em câmara fria (Figura $1 \mathrm{~A}$ ). No entanto, a germinação não variou ao longo do armazenamento e se manteve em patamares elevados em sementes das demais cultivares. Sementes de cinco cultivares (Figura $1 \mathrm{~B}$ ), armazenadas sob condições não controladas, apresentaram comportamento quadrático ao longo do armazenamento, com germinações máximas estimadas entre 2,5 (75 dias) e 3,07 meses (92 dias). A partir de 92 dias, iniciou-se a redução da germinação. Em todas as cultivares, as reduções mais bruscas ocorreram após seis meses de armazenamento em condições não controladas. Martins-Filho et al. (2001) relataram aumento da germinação de sementes de soja em até $60 \mathrm{a}$ 
90 dias, em geral, após o armazenamento em condição ambiente, em razão da redução da incidência de fungos de campo sobre as sementes armazenadas; a partir deste período, iniciou-se o declínio da germinação, com redução maior a partir de 120 a 150 dias de armazenamento. O efeito para sementes da cultivar TMG 1176 foi de terceiro grau, com decréscimo na germinação antes de dois meses de armazenamento, e pequeno incremento aos seis meses, seguido de redução mais acentuada (Figura $1 \mathrm{~B}$ ).

Estes resultados evidenciam a eficiência na manutenção da viabilidade das sementes de soja em elevados patamares, quando armazenadas em câmara fria, principalmente após seis meses de armazenamento. Aos oito meses de armazenamento em câmara fria, as sementes de todas as cultivares foram superiores às armazenadas em condição não controlada (Tabela 1). Vieira et al. (2013a) verificaram que a qualidade de sementes de soja pode ser mantida por até 12 meses, quando armazenadas a $10^{\circ} \mathrm{C}$.

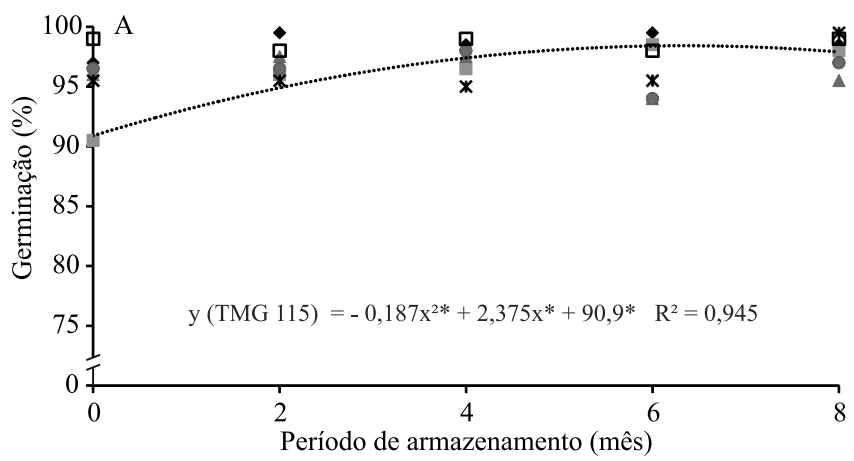

No armazenamento em condições não controladas, verificou-se que a germinação das sementes da cultivar TMG 1176 foi inferior à das demais aos dois, quatro, seis e oito meses de armazenamento (Tabela 1). Assim, infere-se que o potencial de armazenamento de sementes de soja está ligado ao genótipo. Martins-Filho et al. (2001) relataram que a longevidade das sementes de soja armazenadas em condição não controlada foi influenciada por características inerentes à própria espécie. Estes autores verificaram também a deterioração total após 240 dias de armazenamento, tempo este que, no presente trabalho, proporcionou apenas redução acentuada de viabilidade (Tabela 1).

Quanto ao vigor, estimado por meio do envelhecimento acelerado, as variações ao longo do armazenamento em câmara fria também foram pequenas, tendo apresentado valores, em geral, acima de $90 \%$ (Figura $2 \mathrm{~A}$ ). Isto mostra a eficiência na manutenção do vigor das sementes nestas

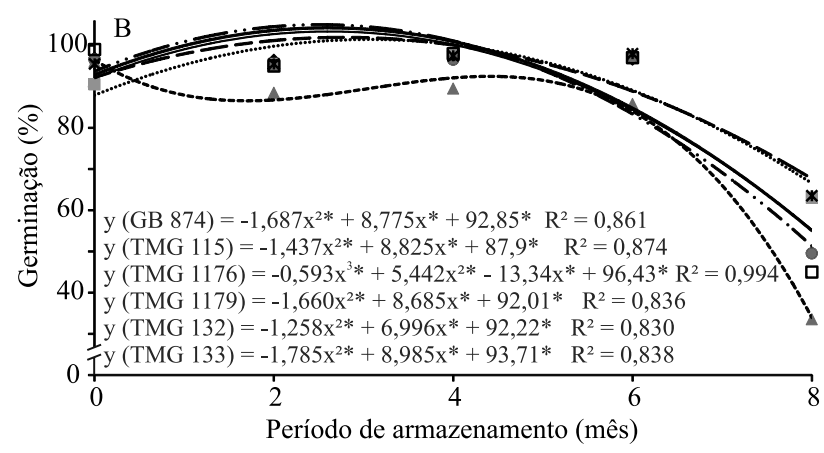

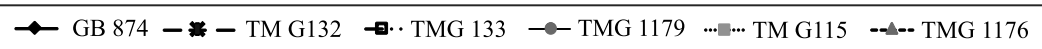

Figura 1. Germinação de sementes de cultivares de soja, após diferentes períodos de armazenamento $(0,2,4,6$ e 8 meses $)$ em dois ambientes: A, câmara fria $\left(10^{\circ} \mathrm{C}\right.$ e $50 \%$ de umidade relativa); e B, armazém convencional em condições não controladas $\left(22^{\circ} \mathrm{C}\right.$ e $73 \%$ de umidade relativa $)$.

Tabela 1. Germinação (\%) de sementes de cultivares de soja, após diferentes períodos de armazenamento $(0,2,4,6$ e 8 meses) em dois ambientes: câmara fria (CF) e armazém convencional em condições não controladas (NC) ${ }^{(1)}$.

\begin{tabular}{|c|c|c|c|c|c|c|c|c|c|c|}
\hline \multirow[t]{2}{*}{ Cultivar } & \multicolumn{2}{|c|}{0 meses } & \multicolumn{2}{|c|}{2 meses } & \multicolumn{2}{|c|}{4 meses } & \multicolumn{2}{|c|}{6 meses } & \multicolumn{2}{|c|}{8 meses } \\
\hline & $\mathrm{CF}$ & $\mathrm{NC}$ & $\mathrm{CF}$ & $\mathrm{NC}$ & $\mathrm{CF}$ & $\mathrm{NC}$ & $\mathrm{CF}$ & $\mathrm{NC}$ & $\mathrm{CF}$ & $\mathrm{NC}$ \\
\hline TMG 132 & 96Aa & $96 \mathrm{Aa}$ & $96 \mathrm{Aa}$ & $96 \mathrm{Aa}$ & $95 \mathrm{Aa}$ & 98Aa & $96 \mathrm{Ab}$ & 98Aa & $100 \mathrm{Aa}$ & $64 \mathrm{Ba}$ \\
\hline TMG 133 & 99Aa & 99Aa & $98 \mathrm{Aa}$ & $95 \mathrm{Aa}$ & 99Aa & 98Aa & $98 \mathrm{Aa}$ & 97Aa & 99Aa & $45 \mathrm{Bc}$ \\
\hline GB 874 & $97 \mathrm{Aa}$ & 97Aa & $100 \mathrm{Aa}$ & $97 \mathrm{Aa}$ & 99Aa & 98Aa & $100 \mathrm{Aa}$ & $97 \mathrm{Aa}$ & 99Aa & $50 \mathrm{Bb}$ \\
\hline TMG 115 & $91 \mathrm{Ab}$ & $91 \mathrm{Ab}$ & $96 \mathrm{Aa}$ & $96 \mathrm{Aa}$ & $97 \mathrm{Aa}$ & 98Aa & 99Aa & $97 \mathrm{Aa}$ & $98 \mathrm{Aa}$ & $63 \mathrm{Ba}$ \\
\hline TMG 1179 & $97 \mathrm{Aa}$ & 97Aa & $97 \mathrm{Aa}$ & $95 \mathrm{Aa}$ & 98Aa & 97Aa & $94 \mathrm{Ab}$ & $97 \mathrm{Aa}$ & $97 \mathrm{Aa}$ & $50 \mathrm{Bb}$ \\
\hline TMG 1176 & $96 \mathrm{Aa}$ & $96 \mathrm{Aa}$ & $98 \mathrm{Aa}$ & $89 \mathrm{Bb}$ & 98Aa & $90 \mathrm{Bb}$ & $94 \mathrm{Ab}$ & $86 \mathrm{Bb}$ & $96 \mathrm{Aa}$ & $34 \mathrm{Bd}$ \\
\hline
\end{tabular}

${ }^{(1)}$ Médias seguidas de letras iguais, minúsculas nas colunas e maiúsculas nas linhas, em cada época de armazenamento, não diferem entre si, pelo teste Scott-Knott, a $5 \%$ de probabilidade. Câmara fria: $10^{\circ} \mathrm{C}$ e $50 \%$ de umidade relativa. Armazém convencional em condições não controladas: $22^{\circ} \mathrm{C}$ e $73 \%$ de umidade relativa. 
condições. Verificou-se que, com dois meses de armazenamento, o vigor das sementes armazenadas em câmara fria e em condição ambiente não diferiram (Tabela 2). Porém, após quatro meses, as sementes das cultivares GB 874, TMG 115 e TMG 1179 que foram armazenadas em câmara fria expressaram maior vigor, em comparação às armazenadas em condições não controladas. O mesmo fato foi observado nas sementes de todas as cultivares, exceto GB 874 e TMG 1176, após seis meses de armazenamento. Após oito meses, todas as sementes armazenadas em câmara fria apresentaram maior vigor (Tabela 2).

$\mathrm{O}$ vigor das sementes armazenadas em condições não controladas apresentou tendência quadrática, cujos valores máximos foram observados entre 2,35 $(70,5)$ e 2,55 meses (76,6 dias). Até quatro meses, houve redução do vigor, mas os valores se mantiveram elevados. Após esse período, verificou-se redução brusca do vigor, mais acentuada aos seis meses e,

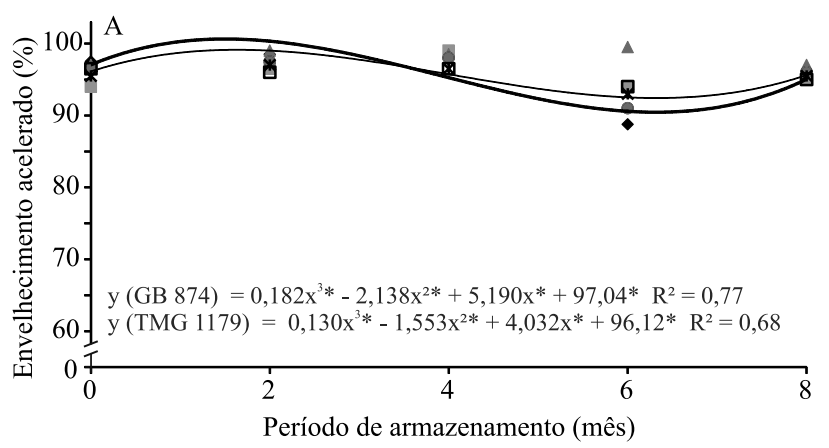

principalmente, aos oito meses de armazenamento (Figura $2 \mathrm{~B}$ ).

Pelo teste de frio, constatou-se que o vigor foi mantido em sementes armazenadas em câmara fria (Figura $3 \mathrm{~A}$ ), ao longo dos oito meses de armazenamento, exceto para sementes da cultivar TMG 1179, em que se verificou redução de vigor na última época de avaliação. A partir de dois meses, as sementes armazenadas em câmara fria, em geral, apresentaram maior vigor em relação às armazenadas em condição ambiente, com maior diferença aos oito meses de armazenamento (Tabela 3), o que confirma as vantagens do armazenamento de sementes de soja em câmara fria a $10^{\circ} \mathrm{C}$.

No armazenamento em condições ambientes, o vigor expressou comportamento quadrático para todas as cultivares, com picos obtidos entre 1,82 $(54,6)$ e 2,6 meses $(78,2$ dias). Houve redução do vigor, com menor intensidade até os quatro meses de armazenamento e, a partir dessa época, a diminuição

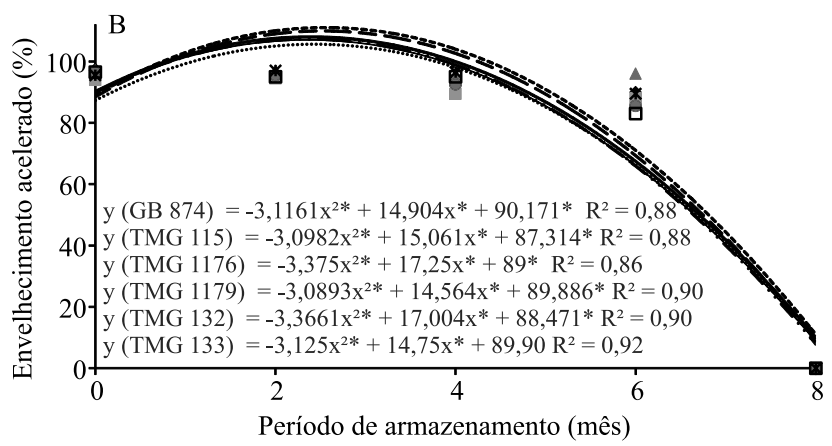

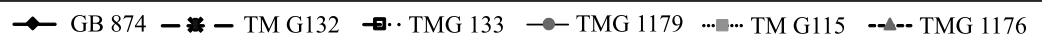

Figura 2. Germinação de sementes de cultivares de soja, após o envelhecimento acelerado, em função de diferentes períodos de armazenamento $\left(0,2,4,6\right.$ e 8 meses) em dois ambientes: A, câmara fria, a $10^{\circ} \mathrm{C}$ e $50 \%$ de umidade relativa; e B, armazém convencional em condições não controladas, a $22^{\circ} \mathrm{C}$ e $73 \%$ de umidade relativa.

Tabela 2. Germinação (\%) de sementes de cultivares de soja, após o envelhecimento acelerado, em função de diferentes períodos de armazenamento ( $0,2,4,6$ e 8 meses) em dois ambientes: câmara fria (CF) e armazém convencional em condições não controladas $(\mathrm{NC})^{(1)}$.

\begin{tabular}{|c|c|c|c|c|c|c|c|c|c|c|}
\hline \multirow[t]{2}{*}{ Cultivar } & \multicolumn{2}{|c|}{0 meses } & \multicolumn{2}{|c|}{2 meses } & \multicolumn{2}{|c|}{4 meses } & \multicolumn{2}{|c|}{6 meses } & \multicolumn{2}{|c|}{8 meses } \\
\hline & $\mathrm{CF}$ & $\mathrm{NC}$ & $\mathrm{CF}$ & $\mathrm{NC}$ & $\mathrm{CF}$ & $\mathrm{NC}$ & $\mathrm{CF}$ & $\mathrm{NC}$ & $\mathrm{CF}$ & $\mathrm{NC}$ \\
\hline TMG 132 & $96 \mathrm{Aa}$ & $96 \mathrm{Aa}$ & $97 \mathrm{Aa}$ & $97 \mathrm{Aa}$ & $97 \mathrm{Aa}$ & $97 \mathrm{Aa}$ & $93 \mathrm{Ab}$ & $90 \mathrm{Bb}$ & $96 \mathrm{Aa}$ & $0 \mathrm{Ba}$ \\
\hline TMG 133 & $97 \mathrm{Aa}$ & $97 \mathrm{Aa}$ & $96 \mathrm{Aa}$ & $95 \mathrm{Aa}$ & $97 \mathrm{Aa}$ & $95 \mathrm{Aa}$ & $94 \mathrm{Ab}$ & $83 \mathrm{Bc}$ & $95 \mathrm{Aa}$ & $0 \mathrm{Ba}$ \\
\hline GB 874 & 98Aa & $98 \mathrm{Aa}$ & 99Aa & $96 \mathrm{Aa}$ & 98Aa & $92 \mathrm{Bb}$ & $89 \mathrm{Ac}$ & $90 \mathrm{Ab}$ & $96 \mathrm{Aa}$ & $0 \mathrm{Ba}$ \\
\hline TMG 115 & $94 \mathrm{Aa}$ & $94 \mathrm{Aa}$ & $97 \mathrm{Aa}$ & $95 \mathrm{Aa}$ & $99 \mathrm{Aa}$ & $90 \mathrm{Bb}$ & $94 \mathrm{Ab}$ & $88 \mathrm{Bb}$ & $95 \mathrm{Aa}$ & $0 \mathrm{Ba}$ \\
\hline TMG 1179 & $97 \mathrm{Aa}$ & $97 \mathrm{Aa}$ & 98Aa & $96 \mathrm{Aa}$ & 98Aa & $93 \mathrm{Bb}$ & $91 \mathrm{Ac}$ & $86 \mathrm{Bc}$ & 96Aa & $0 \mathrm{Ba}$ \\
\hline TMG 1176 & $97 \mathrm{Aa}$ & 97Aa & 99Aa & 97Aa & $99 \mathrm{Aa}$ & $95 \mathrm{Aa}$ & $100 \mathrm{Aa}$ & $96 \mathrm{Aa}$ & $97 \mathrm{Aa}$ & $0 \mathrm{Ba}$ \\
\hline
\end{tabular}

${ }^{(1)}$ Médias seguidas de letras iguais, minúsculas nas colunas e maiúsculas nas linhas, em cada época de armazenamento, não diferem entre si, pelo teste Scott-Knott, a $5 \%$ de probabilidade. Câmara fria: $10^{\circ} \mathrm{C}$ e $50 \%$ de umidade relativa. Armazém convencional em condições não controladas: $22^{\circ} \mathrm{C}$ e $73 \%$ de umidade relativa. 
foi drástica (Figura 3 B). Martins-Filho et al. (2001) constataram que, a partir de 210 dias de armazenamento em condição não controlada, as sementes de soja apresentaram vigor nulo. Para Cunha et al. (2009), o armazenamento em condição ambiente após seis meses reduziu o vigor das sementes de soja.

As médias obtidas no teste de frio diferiram entre cultivares, para as sementes de armazenadas por dois, quatro e seis meses em condições não controladas. Sementes de TMG 1176 apresentaram vigor inferior às demais aos dois meses, época em que não diferiu de TMG 132, e aos quatro e seis meses de armazenamento (Tabela 3).

Quanto à expressão de malato desidrogenase (MDH), as principais diferenças foram verificadas com o avanço do período de armazenamento, aos seis e oito meses. Nestes períodos de armazenamento, as sementes armazenadas em câmara fria apresentaram maior atividade da $\mathrm{MDH}$ em comparação às armazenadas em armazém convencional, em razão do maior estresse sofrido em condições não controladas, principalmente aos oito meses de armazenamento (Figura 4). Vieira et al. (2013b) verificaram decréscimo de atividade da $\mathrm{MDH}$, a partir de seis meses de armazenamento a $10^{\circ} \mathrm{C}$ e a $25^{\circ} \mathrm{C}$, porém, com efeito maior aos nove e doze meses de armazenamento a $25^{\circ} \mathrm{C}$.

Sementes da cultivar TMG 1176 apresentaram as maiores diferenças quanto à atividade da $\mathrm{MDH}$ ao longo do armazenamento (Figura 4). Sementes armazenadas em condição não controlada, após 4 meses de armazenamento, apresentaram aumento da expressão da enzima, porém, com o avanço do armazenamento, esta expressão diminuiu. Nas sementes armazenadas em câmara fria, a atividade da MDH se manteve elevada até o final do armazenamento. A germinação das sementes da TMG 1176, armazenadas em ambiente controlado, não variou ao longo do tempo (Figura $2 \mathrm{~A}$ ); no entanto, em condição ambiente, houve queda da germinação
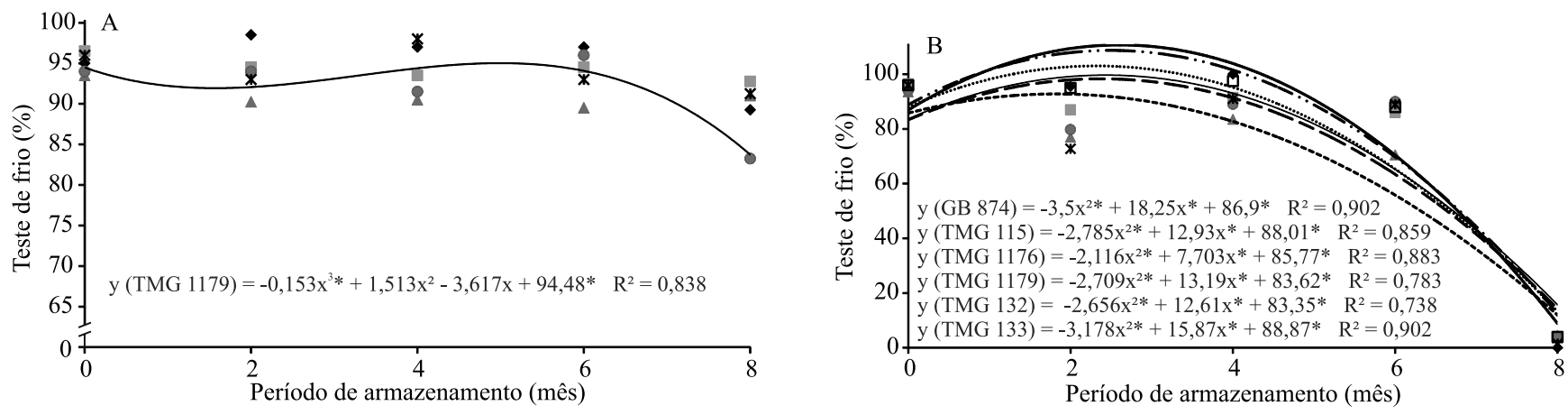

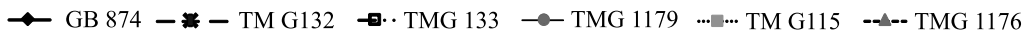

Figura 3. Emergência de sementes de cultivares de soja, após o teste de frio, em função de diferentes períodos de armazenamento $\left(0,2,4,6\right.$ e 8 meses) em dois ambientes: A, câmara fria, a $10^{\circ} \mathrm{C}$ e $50 \%$ de umidade relativa; e $\mathrm{B}$, armazém convencional em condições não controladas, a $22^{\circ} \mathrm{C}$ e $73 \%$ de umidade relativa.

Tabela 3. Emergência (\%) de sementes de cultivares de soja, após o teste de frio, em função de diferentes períodos de armazenamento $(0,2,4,6$ e 8 meses) em dois ambientes: câmara fria (CF) e armazém convencional em condições não controladas $(\mathrm{NC})^{(1)}$.

\begin{tabular}{|c|c|c|c|c|c|c|c|c|c|c|}
\hline \multirow[t]{2}{*}{ Cultivar } & \multicolumn{2}{|c|}{0 meses } & \multicolumn{2}{|c|}{2 meses } & \multicolumn{2}{|c|}{4 meses } & \multicolumn{2}{|c|}{6 meses } & \multicolumn{2}{|c|}{8 meses } \\
\hline & $\mathrm{CF}$ & $\mathrm{NC}$ & $\mathrm{CF}$ & $\mathrm{NC}$ & $\mathrm{CF}$ & $\mathrm{NC}$ & $\mathrm{CF}$ & $\mathrm{NC}$ & $\mathrm{CF}$ & $\mathrm{NC}$ \\
\hline TMG 132 & $96 \mathrm{Aa}$ & $96 \mathrm{Aa}$ & $93 \mathrm{Aa}$ & $73 \mathrm{Bb}$ & $98 \mathrm{Ab}$ & $91 \mathrm{Bb}$ & $93 \mathrm{Aa}$ & $89 \mathrm{Ba}$ & $91 \mathrm{Aa}$ & $2 \mathrm{Ba}$ \\
\hline TMG 133 & $96 \mathrm{Aa}$ & $96 \mathrm{Aa}$ & $97 \mathrm{Aa}$ & $95 \mathrm{Aa}$ & $97 \mathrm{Aa}$ & $98 \mathrm{Aa}$ & 96Aa & $88 \mathrm{Ba}$ & $92 \mathrm{Aa}$ & $4 \mathrm{Ba}$ \\
\hline GB 874 & $95 \mathrm{Aa}$ & $95 \mathrm{Aa}$ & 99Aa & 96Аa & 97Aa & $100 \mathrm{Aa}$ & 97Aa & 90Aa & 89Aa & $0 \mathrm{Ba}$ \\
\hline TMG 115 & 97Aa & 97Aa & $95 \mathrm{Aa}$ & $87 \mathrm{Ba}$ & $94 \mathrm{Ab}$ & $92 \mathrm{Ab}$ & $95 \mathrm{Aa}$ & $86 \mathrm{Ba}$ & $93 \mathrm{Aa}$ & $4 \mathrm{Ba}$ \\
\hline TMG 1179 & 94Aa & 94Aa & $94 \mathrm{Aa}$ & $80 \mathrm{Bb}$ & $92 \mathrm{Ab}$ & $89 \mathrm{Ab}$ & 96Aa & $90 \mathrm{Aa}$ & $83 \mathrm{Ab}$ & $4 \mathrm{Ba}$ \\
\hline TMG 1176 & 94Aa & 94Aa & $90 \mathrm{Aa}$ & $77 \mathrm{Bb}$ & $91 \mathrm{Ab}$ & $84 \mathrm{Bc}$ & $90 \mathrm{Aa}$ & $71 \mathrm{Bb}$ & $91 \mathrm{Aa}$ & $5 \mathrm{Ba}$ \\
\hline
\end{tabular}

${ }^{(1)}$ Médias seguidas de letras iguais, minúsculas nas colunas e maiúsculas nas linhas, em cada época de armazenamento, não diferem entre si, pelo teste Scott-Knott, a $5 \%$ de probabilidade. Câmara fria: $10^{\circ} \mathrm{C}$ e $50 \%$ de umidade relativa. Armazém convencional em condições não controladas: $22^{\circ} \mathrm{C}$ e $73 \%$ de umidade relativa. 
aos dois, quatro e seis meses, com decréscimo maior aos oito meses (Figura $2 \mathrm{~B}$ ). As principais alterações relacionadas ao processo de deterioração são a redução da atividade respiratória, a degradação e a inativação de enzimas (Copeland \& McDonald, 2001).

Ao longo do armazenamento, a expressão de álcool desidrogenase (ADH) foi, em geral, maior nas sementes em câmara fria, em comparação às armazenadas em condições não controladas, principalmente aos seis e oito meses (Figura 5). A atividade dessa enzima contribuiu para a manutenção da qualidade das sementes no armazenamento em câmara fria (Figuras 1, 2 e 3). Essa enzima é relevante, pois converte o acetaldeído em etanol, um composto com menor toxicidade, e reduz a velocidade do processo de deterioração (Veiga et al., 2010). Assim, as sementes ficam menos suscetíveis à ação deletéria do acetaldeído com a maior atividade da ADH.

Entre as cultivares, houve diferença na expressão da ADH, com maior atividade em sementes de TMG 133, TMG 132 e GB 874, e menor atividade em TMG 1176,

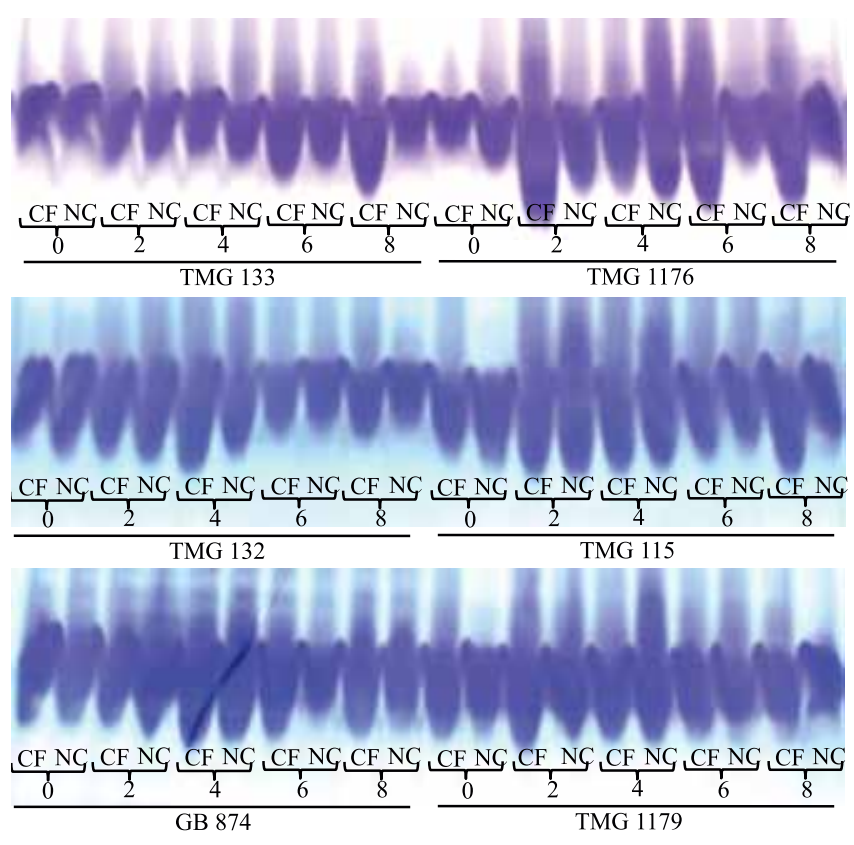

Figura 4. Expressão isoenzimática da malato desidrogenase (MDH), em sementes de soja das cultivares TMG 133 RR, TMG 1176 RR, TMG 132 RR, TMG 115 RR, GB 874 RR e TMG $1179 \mathrm{RR}$, após diferentes períodos de armazenamento $(0,2,4,6$ e 8 meses) em dois ambientes: câmara fria (CF), a $10^{\circ} \mathrm{C}$ e $50 \%$ de umidade relativa; e armazém convencional em condições não controladas (NC), a $22^{\circ} \mathrm{C}$ e $73 \%$ de umidade relativa.
TMG 115 e TMG 1179 (Figura 5). Carvalho et al. (2014) constataram maiores expressões de ADH em sementes de cultivares que apresentaram melhor qualidade fisiológica.

Em câmara fria, em geral, as sementes apresentaram maior atividade da esterase do que as sementes armazenadas em condições não controladas, ao longo do armazenamento (Figura 6). A esterase atua em processo relevante para a retomada do crescimento do eixo embrionário e quebra de lipídeos, principalmente em sementes oleaginosas, como é o caso da soja (Veiga et al., 2010). Vieira et al. (2013b) verificaram que a atividade da esterase diminuiu a partir do sexto mês, tendo ocorrido o desaparecimento das bandas aos nove e doze meses de armazenamento.

Sementes da TMG 1176 armazenadas em câmara fria apresentaram maior atividade da esterase do que as armazenadas em condições não controladas (Figura 6), aos dois meses de armazenamento e, a partir desse período, apresentaram também maiores valores de germinação (Tabela 1) e vigor (Tabela 3 ), diferenças que perduraram ao longo do armazenamento. Sementes de TMG 133 apresentaram maiores expressões da esterase em câmara fria, após seis meses de armazenamento e,

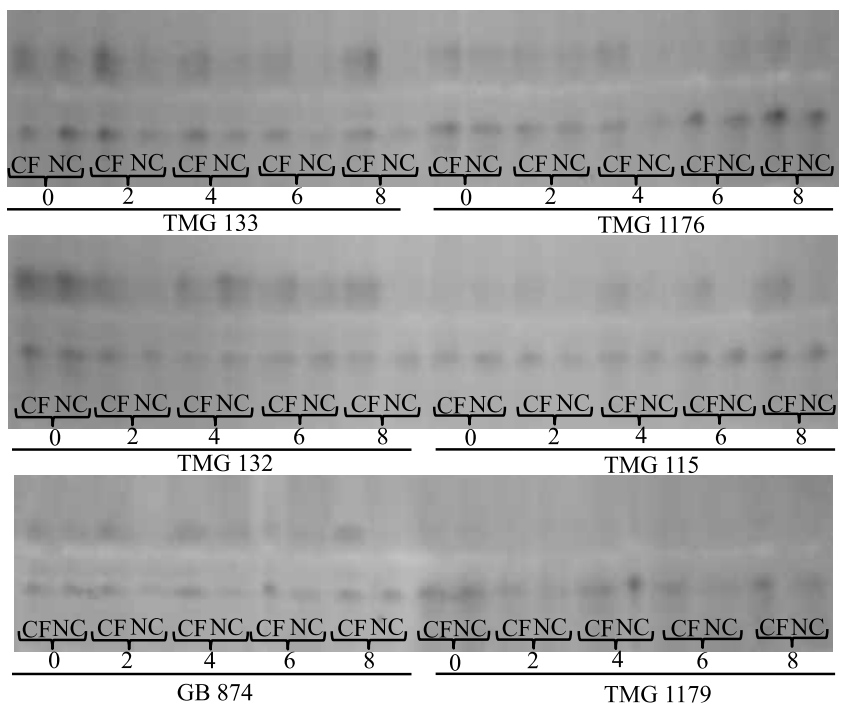

Figura 5. Expressão isoenzimática da álcool desidrogenase (ADH), em sementes de soja das cultivares TMG 133 RR, TMG 1176 RR, TMG 132 RR, TMG 115 RR, GB 874 RR e TMG $1179 \mathrm{RR}$, após diferentes períodos de armazenamento $(0,2,4,6$ e 8 meses) em dois ambientes: câmara fria (CF), a $10^{\circ} \mathrm{C}$ e $50 \%$ de umidade relativa; e armazém convencional em condições não controladas (NC), a $22^{\circ} \mathrm{C}$ e $73 \%$ de umidade relativa. 
também, maior vigor após esse período (Tabelas 2 e 3). Situação semelhante também se observou nas sementes da GB 874 após oito meses de armazenamento.

Em sementes das cultivares TMG 133, TMG 132, GB 874 e TMG 1179, verificou-se queda na expressão da isocitrato liase (ICL), com o avanço do armazenamento, principalmente aos seis e oito meses (Figura 7). Porém, diferença entre a manutenção de atividade de ICL, em consequência do ambiente de armazenamento, foi perceptível somente nas cultivares TMG 133 e TMG 132 aos seis e oito meses, e TMG 1179 aos oito meses de armazenamento, com expressão maior em sementes armazenadas em câmara fria. Martins et al. (2000) constataram a importância da ICL e do ciclo do glioxilato, para o processo germinativo em sementes

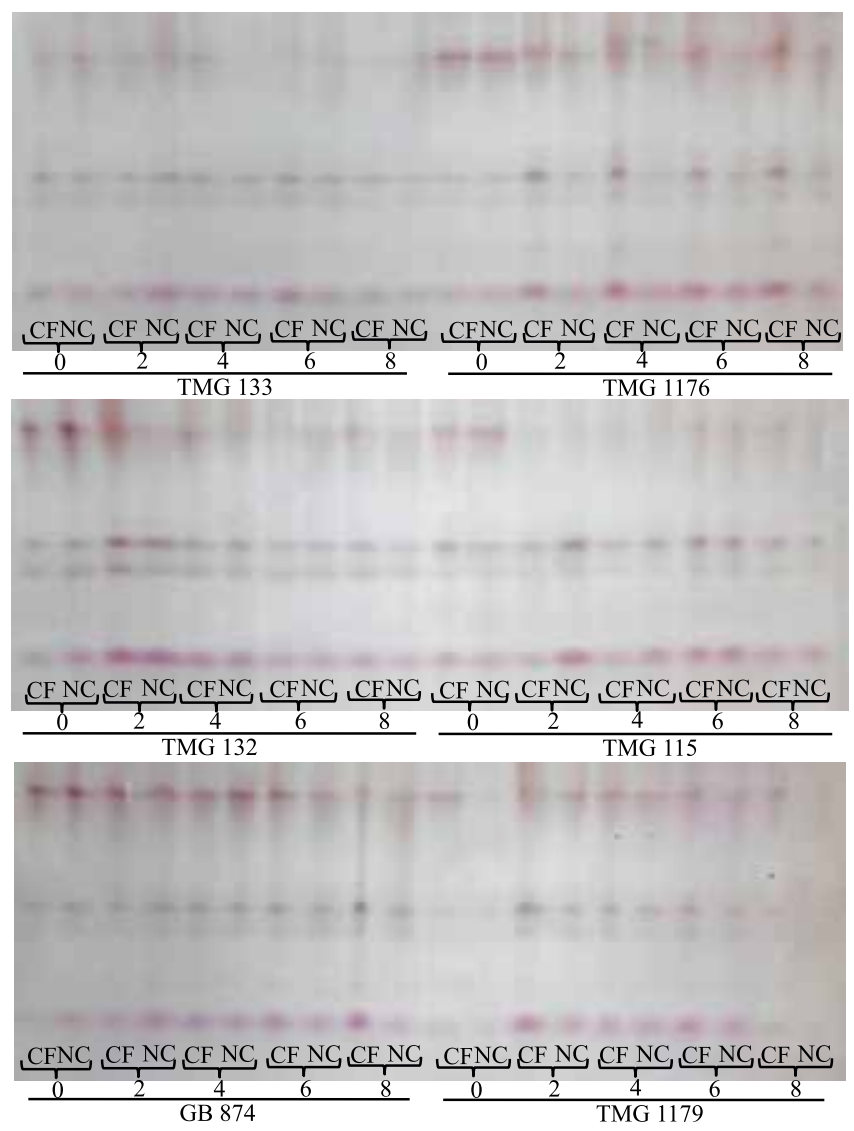

Figura 6. Expressão isoenzimática da esterase (EST), em sementes de soja das cultivares TMG 133 RR, TMG 1176 RR, TMG 132 RR, TMG 115 RR, GB 874 RR e TMG 1179 $\mathrm{RR}$, após diferentes períodos de armazenamento $(0,2,4,6$ e 8 meses) em dois ambientes: câmara fria (CF), a $10^{\circ} \mathrm{C}$ e $50 \%$ de umidade relativa; e armazém convencional em condições não controladas (NC), a $22^{\circ} \mathrm{C}$ e $73 \%$ de umidade relativa. de soja, e também diferenças de atividade da ICL entre cultivares.

Para superóxido dismutase (SOD), somente nas sementes de TMG 1176 houve diferenças consistentes na expressão, ao longo do armazenamento (Figura 8). Verificou-se incremento da atividade dessa enzima aos 2 e 4 meses de armazenamento, independentemente da condição de armazenamento. Contudo, após 6 e 8 meses de armazenamento sob condições não controladas, a expressão da SOD diminuiu, ao passo que, para as sementes armazenadas em câmara fria, a atividade dessa enzima se manteve. Sementes de TMG 1176 armazenadas em câmara fria apresentaram melhor potencial fisiológico do que as armazenadas em condições não controladas (Tabelas 1, 2 e 3 ).

É importante a manutenção da atividade de isoenzimas dos sistemas antioxidantes, como a (SOD) e a $\mathrm{PO}$, pois atuam na remoção e redução de espécies reativas de oxigênio (ERO) que podem causar danos celulares (Møller et al., 2007; Deuner et al., 2011) e afetar a qualidade das sementes.

A expressão da PO foi detectada apenas nas sementes da cultivar GB874 (Figura 9). Para sementes de GB 874, após 2 e 4 meses de armazenamento, a atividade da PO foi maior, em comparação ao início do

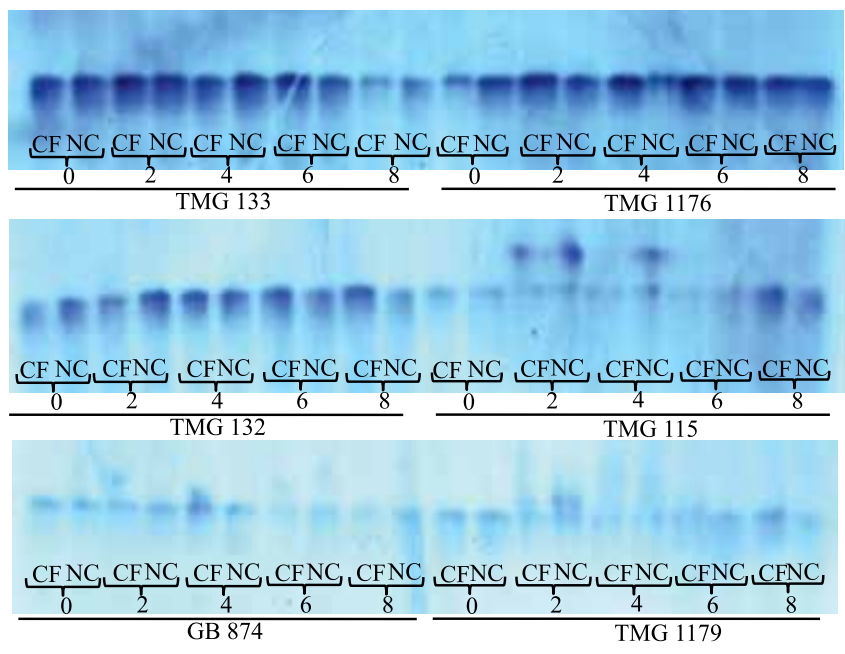

Figura 7. Expressão isoenzimática da isocitrato liase (ICL), em sementes de soja das cultivares TMG 133 RR, TMG 1176 RR, TMG 132 RR, TMG 115 RR, GB 874 RR e TMG $1179 \mathrm{RR}$, após diferentes períodos de armazenamento $(0,2$, 4,6 e 8 meses) em dois ambientes: câmara fria (CF), a $10^{\circ} \mathrm{C}$ e $50 \%$ de umidade relativa; e armazém convencional em condições não controladas ( $\mathrm{NC})$, a $22^{\circ} \mathrm{C}$ e $73 \%$ de umidade relativa. 

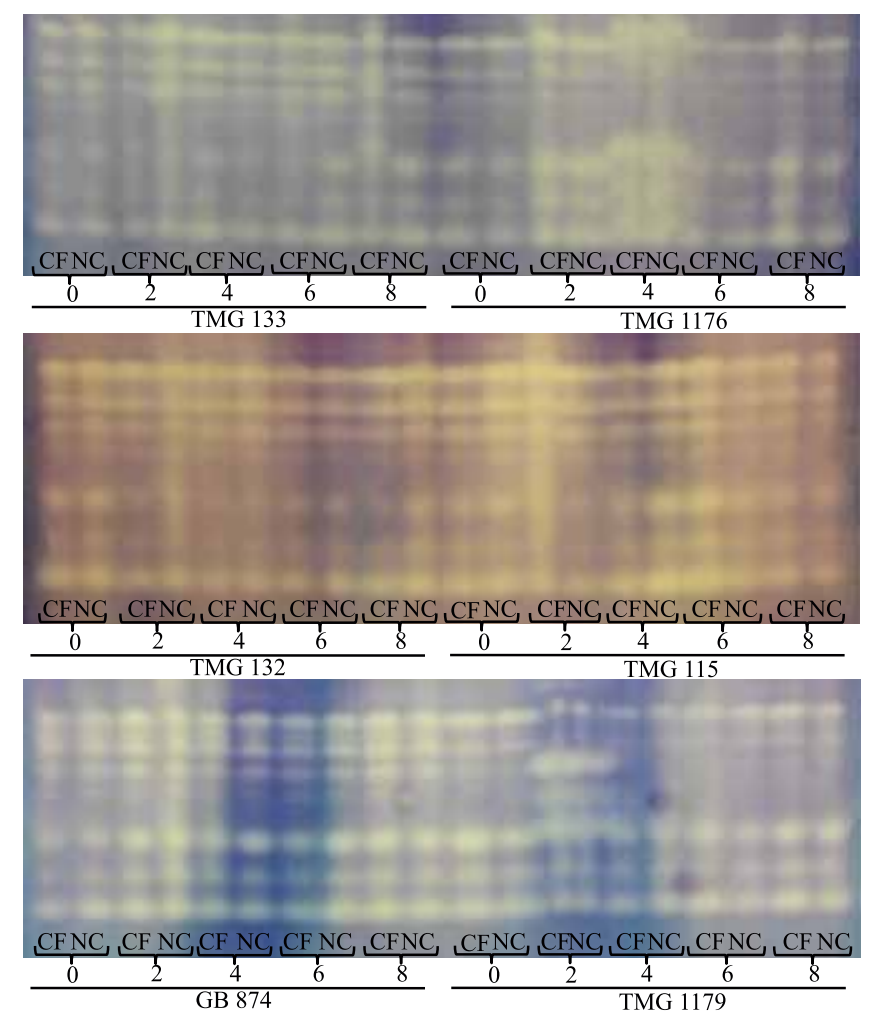

Figura 8. Expressão isoenzimática da superóxido dismutase (SOD), em sementes de soja das cultivares TMG $133 \mathrm{RR}$, TMG 1176 RR, TMG 132 RR, TMG 115 RR, GB 874 RR e TMG $1179 \mathrm{RR}$, após diferentes períodos de armazenamento $(0,2,4,6$ e 8 meses) em dois ambientes: câmara fria $(\mathrm{CF})$, a $10^{\circ} \mathrm{C}$ e $50 \%$ de umidade relativa; e armazém convencional em condições não controladas (NC), a $22^{\circ} \mathrm{C}$ e $73 \%$ de umidade relativa.

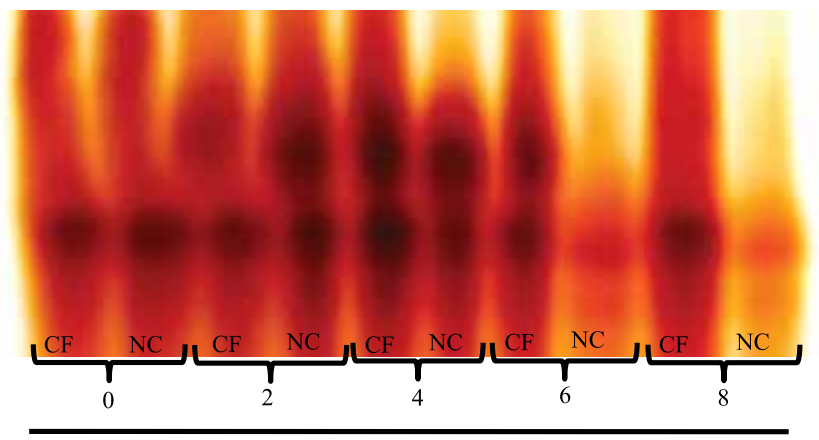

GB 874

Figura 9. Expressão isoenzimática da peroxidase (PO), em sementes de soja da cultivar GB 874 RR, após diferentes períodos de armazenamento (0,2, 4, 6 e 8 meses) em dois ambientes: câmara fria $(\mathrm{CF})$, a $10^{\circ} \mathrm{C}$ e $50 \%$ de umidade relativa; e armazém convencional em condições não controladas (NC), a $22^{\circ} \mathrm{C}$ e $73 \%$ de umidade relativa. armazenamento, para ambos os ambientes (Figura 9). Após 6 e 8 meses de armazenamento, a expressão da PO em sementes armazenadas em condição não controlada diminuiu, porém, nas sementes armazenadas em câmara fria, a expressão se manteve, apenas com pequena queda aos oito meses de armazenamento. $\mathrm{O}$ armazenamento em câmara fria contribuiu para a conservação da conformação e atividade de sistemas isoenzimáticos, principalmente aos 6 e 8 meses, o que se verificou também para $\mathrm{MDH}, \mathrm{ADH}, \mathrm{EST}$, ICL e SOD, e influenciou positivamente a qualidade fisiológica das sementes (Tabelas 1, 2 e 3).

\section{Conclusões}

1. Sementes de soja armazenadas em câmara fria e seca mantêm a germinação e o vigor por período de tempo indeterminado; no entanto, em condições não controladas, a germinação e o vigor são reduzidos, principalmente após seis meses de armazenamento.

2. Os genótipos de soja apresentam diferentes níveis de tolerância ao armazenamento.

3. Asexpressõesisoenzimáticassão variáveis conforme o genótipo e diferem ao longo do armazenamento.

4. Em sementes armazenadas em condições não controladas, ocorre queda de atividade dos sistemas isoenzimáticos malato desidrogenase, álcool desidrogenase, esterase, isocitrato liase, superóxido dismutase e peroxidase, principalmente após seis meses; no armazenamento em câmaras fria e seca, essas atividades são mantidas.

\section{Agradecimentos}

Ao Conselho Nacional de Desenvolvimento Científico e Tecnológico (CNPq), pela concessão de bolsas; Ao CNPq, à Coordenação de Aperfeiçoamento de Pessoal de Nível Superior (Capes), à Fundação de Amparo à Pesquisa do Estado de Minas Gerais (Fapemig) e Sementes Arco Íris, pelo apoio financeiro.

\section{Referências}

ALFENAS, A.C. (Ed.). Eletroforese e marcadores bioquímicos em plantas e microrganismos. 2.ed. Viçosa: Ed. da UFV, 2006. $627 \mathrm{p}$.

ÁVILA, M.R.; BRACCINI, A. de L. e; SOUZA, C.G.M. de; MANDARINO, J.M.G.; BAZO, G.L.; CABRAL, Y.C.F. Physiological quality, content and activity of antioxidants in 
soybean seeds artificially aged. Revista Brasileira de Sementes, v.34, p.397-407, 2012. DOI: 10.1590/S0101-31222012000300006.

CARVALHO, E.R.; OLIVEIRA, J.A.; VON PINHO, É.V. de R.; COSTA NETO, J. Enzyme activity in soybean seeds produced under foliar application of manganese. Ciência e Agrotecnologia, v.38, p.317-327, 2014. DOI: 10.1590/S1413-70542014000400001.

COPELAND, L.O.; MCDONALD, M.B. Principles of seed science and technology. $4^{\text {th }}$ ed. New York: Chapman and Hall, 2001. 467p. DOI: 10.1007/978-1-4615-1619-4.

CUNHA, J.P.A.R. da; OLIVEIRA, P. de; SANTOS, C.M. dos; MION, R.L. Qualidade das sementes de soja após a colheita com dois tipos de colhedora e dois períodos de armazenamento. Ciência Rural, v.39, p.1420-1425, 2009. DOI: 10.1590/ S0103-84782009005000063.

DEUNER, C.; MAIA, M. de S.; DEUNER, S.; ALMEIDA, A. da S.; MENEGHELLO, G.E. Viabilidade e atividade antioxidante de sementes de genótipos de feijão-miúdo submetidos ao estresse salino. Revista Brasileira de Sementes, v.33, p.711-720, 2011. DOI: $10.1590 / \mathrm{S} 0101-31222011000400013$.

FERREIRA, D.F. Sisvar: a computer statistical analysis system. Ciência e Agrotecnologia, v.35, p.1039-1042, 2011. DOI: 10.1590/S1413-70542011000600001.

FORTI, V.A.; CICERO, S.M.; PINTO, T.L.F. Avaliação da evolução de danos por "umidade" e redução do vigor em sementes de soja, cultivar TMG113-RR, durante o armazenamento, utilizando imagens de raios $\mathrm{X}$ e testes de potencial fisiológico. Revista Brasileira de Sementes, v.32, p.123-133, 2010. DOI: 10.1590/ S0101-31222010000300014.

GRIS, C.F.; VON PINHO, E.V. de R.; ANDRADE, T.; BALDONI, A.; CARVALHO, M.L. de M. Qualidade fisiológica e teor de lignina no tegumento de sementes de soja convencional e transgênica RR submetidas a diferentes épocas de colheita. Ciência e Agrotecnologia, v.34, p.374-381, 2010. DOI: 10.1590/ S1413-70542010000200015.

LIMA, D. de C.; DUTRA, A.S.; PONTES, F.M.; BEZERRA, F.T.C. Storage of sunflower seeds. Revista Ciência Agronômica, v.45, p.361-369, 2014. DOI: 10.1590/S1806-66902014000200018.

MARCOS FILHO, J. Teste de envelhecimento acelerado. In: KRZYZANOWSKI, F.C.; VIEIRA, R.D.; FRANÇA NETO, J. de B. (Ed.). Vigor de sementes: conceitos e testes. Londrina: Abrates, 1999. p.24-32.
MARTINS, C.A.O.; SEDIYAMA, C.S.; OLIVEIRA, M.G. de A.; JOSÉ, I.C.; MOREIRA, M.A.; REIS, M.S.; ROCHA, V.S. Atividade da isocitrato-liase durante a germinação de sementes de soja. Revista Brasileira de Sementes, v.22, p.42-46, 2000.

MARTINS-FILHO, S.; LOPES, J.C.; RANGEL, O.J.P.; TAGLIAFERRE, C. Avaliação da qualidade fisiológica de sementes de soja armazenadas em condições de ambiente natural em Alegre-ES. Revista Brasileira de Sementes, v.23, p.201-208, 2001.

MØLLER, I.M.; JENSEN, P.E.; HANSSON, A. Oxidative modifications to cellular components in plants. Annual Review of Plant Biology, v.58, p.459-481, 2007. DOI: 10.1146/annurev. arplant.58.032806.103946.

REGRAS para análise de sementes. Brasília: Ministério da Agricultura, Pecuária e Abastecimento, 2009. 399p.

SANTOS, H.O. dos. Qualidade fisiológica e expressão de genes durante o desenvolvimento de sementes de pimenta habanero (Capsicum chinense JACQUIM.). 2013. 70p. Tese (Doutorado) Universidade Federal de Lavras, Lavras.

SCHEEREN, B.R.; PESKE, S.T.; SCHUCH, L.O.B.; BARROS, A.C.A. Qualidade fisiológica e produtividade de sementes de soja. Revista Brasileira de Sementes, v.32, p.35-41, 2010. DOI: 10.1590/S0101-31222010000300004.

TIMÓTEO, T.S.; MARCOS FILHO, J. Seed performance of different corn genotypes during storage. Journal of Seed Science, v.35, p.207-215, 2013. DOI: 10.1590/ S2317-15372013000200010.

VEIGA, A.D.; VON PINHO, É.V. de R.; VEIGA, A.D.; PEREIRA, P.H. de A.R.; OLIVEIRA, K.C. de; VON PINHO, R.G. Influência do potássio e da calagem na composição química, qualidade fisiológica e na atividade enzimática de sementes de soja. Ciência e Agrotecnologia, v.34, p.953-960, 2010. DOI: 10.1590/ S1413-70542010000400022.

VIEIRA, B.G.T.L.; BARBOSA, G.F.; BARBOSA, R.M.; VIEIRA, R.D. Structural changes in soybean seed coat due to harvest time and storage. Journal of Food, Agriculture and Environment, v.11, p.625-628, 2013a.

VIEIRA, B.G.T.L.; BARBOSA, R.M.; TREVISOLI, S.H.U.; MAURO, A.O. di; VIEIRA, R.D. Biochemical alterations in soybean seeds with harvesting time and storage temperature. Journal of Food, Agriculture and Environment, v.11, p.887-891, 2013b.

Recebido em 4 de fevereiro de 2014 e aprovado em 14 de novembro de 2014 